특집논문-09-14-4-01

패킷 비디오 네트워크상의 실시간 무기준법 동영상 화질 평가방법 성 덕 구 ${ }^{a)}$, 김 요 한), 한 정 현 ${ }^{a)}$, 신 지 태 ${ }^{\text {a) }}$

\title{
Realtime No-Reference Quality-Assessment Over Packet Video Networks
}

\author{
Dukgu Sung ${ }^{\text {a)}}$, Yohan Kim ${ }^{\text {a)}}$, Junghyun $\mathrm{Han}^{\text {a)}}$, and Jitae Shin ${ }^{\text {a) }}$
}

요 약

기존의 무기준 동영상 화질 평가는 디코딩 픽셀 단에서 평가와 전송 에러를 고려한 비트스트림단에서 화질 평가 방법으로 나눌 수 있다. 기존의 방법은 추가 데이터 필요하고 복잡도와 평가 정확도등의 문제가 있어 실제적인 실시간 화질평가에 적용하기에 문제가 많다. 본 연구에서는 실시간 비디오 전송 환경에서 이용될 수 있는 간단하면서도 정확도가 높은 무기준법 화질 평가 방법 을 제안한다. 본 논문에서 제안된 무기준법 화질평가 방법은 양자화 파라미터, 전송에러정보, 움직임 벡터정보를 이용한다. 제안된 방법을 검증하기 위해서, ITU-T P.910 ACR(Absolute Category Rating)을 사용하여, 기존의 전체 기준법과 주관적 화질 평가 대비 의 상관도를 비교하였는데 제안방법이 $85 \%$ 이상의 상관도를 보여 주었다.

\begin{abstract}
No-Reference video-quality assessments are divided into two kinds of metrics based on decoding pixel domain or the bitstream one. Traditional full-/reduced- reference methods have difficulty to be deployed as realtime video transmission because it has problems of additional data, complexity, and assessment accuracy. This paper presents simple and highly accurate no-reference video-quality assessment in realtime video transmission. Our proposed method uses quantization parameter, motion vector, and information of transmission error. To evaluate performance of the proposed algorithm, we perform subjective test of video quality with the ITU-T P.910 Absolute Category Rating(ACR) method and compare our proposed algorithm with the subjective quality assessment method. Experimental results show the proposed quality metric has a high correlation (85\%) in terms of subjective quality assessment.
\end{abstract}

Keyword : Video Quality Assessment, No-Reference, MOS, Perceptual, ACR

\section{I. 서 론}

객관적인 화질 평가 방법으로 널리 사용되고 있는 PSNR

a) 성균관대학교 정보통신공학부

School of Information \& Communication Eng., Sungkyunkwan Univ.

\# 교신저자 : 신지태 (jtshin@skku.edu)

· 본 과제(결과물)는 지식경제부의 지원으로 수행한 에너지자원인력양성 사업의 연구결과입니다.

· 접수일(2009년3월16일),수정일(2009년6월22일),게재 확정일(2009년6월 22일)
(Peak Signal to Noise Ratio)은 인간의 인지적 화질 평가 (Human Visual System)와 상관도가 떨어진다는 사실이 기 존의 연구에 의해 알려졌다 ${ }^{[1]}$. 사람의 시각특성과 비슷한 방법을 개발하기 위해 표준화 단체인 VQEG(Video Quality Expert Group $)^{[2]}$ 과 같은 단체에서는 인지적 화질평가 방법 의 표준을 정하고 있다. 인지적인 화질평가 방법은 IPTV나 모바일 IPTV와 같은 서비스에서 사용자 관점에서 품질을 보장하기 위해서 중요하다. 사업자는 사용자 관점에서의 품 
질을 측정하고 이를 이용하여 적절한 서비스 파라미터를 조 절함으로써 서비스의 품질을 유지 시킬 수 있다. 인지적인 화질 평가 방법은 전체기준법(Full Refer ence), 부분기준법 (Reduced Reference), 무기준법(No Reference)로 나누어진 다. 전체기준법은 수신영상과 원본영상과의 비교를 통하여 화질평가를 수행한다. 부분기준법은 수신영상과 원본영상 의 정보를 이용하여 화질 평가를 수행한다. 무기준법은 수신 된 동영상만으로 화질 평가를 수행한다. 하지만 전체 기준법 과 부분기준법은 화질 평가를 위한 추가적인 정보가 필요하 기 때문에 실시간 동영상 전송에는 적합하지 않다.

본 논문에서는 무기준법에 의한 실시간 동영상 화질 평 가를 위해 화질평가 파라미터와 주관적 화질평가로 얻어진 실제 화질지수와의 연관성을 이용하여, 수신된 동영상의 화질을 예측한다. 화질 평가 파라미터는 복호화과정에서 추출할 수 있는 양자화 파라미터와 움직임벡터 정보와 전 송과정에서 발생된 전송에러 정보를 이용한다. 주관적 화 질 평가는 ITU-T P.910 ACR ${ }^{[3]}$ 방법을 사용하였으며, 화질 평가자들은 성균관대학교 정보통신공학부의 학부생 20 명 이 참여하였다.

본 논문의 구성은 다음과 같이 이루어진다. 2 장에서는 객 관적 화질 평가 방법의 종류에 대해서 알아보고, 3 장에서는 주관적 화질 평가와 실험방법, 4장에서는 비트스트림 파라 미터와 전송에러 정보를 이용한 무기준법 화질 평가 방법,
5 장에서는 실험을 통해 기존의 방법과 주관적 화질평가와 의 상관성을 알아본다. 마지막으로 6 장에서 결론과 향후 연 구 방향을 모색한다.

\section{II. 객관적 화질 평가방법}

객관적인 화질 평가 방법의 종류는 그림 1 과 같다.

전체기준법 방법은 원본영상과 수신된 영상의 비교를 통 해서 화질평가를 수행한다. 전체기준법 방법은 송신측의 영상의 픽셀의 값과 수신측의 픽셀의 값을 이용한다. 감소 기준법은 송신측에서 원본영상의 키 파라미터를 추출하여 수신된 비디오의 픽셀값을 이용하여 화질평가를 수행한다. 무기준법은 오로지 수신된 비디오 시퀀스만을 사용하여 화 질 평가를 수행한다. 무기준법 화질 평가 방법은 픽셀단에 서 화질 평가를 수행하는 NR-P(No Reference Pixel) 방법 과 압축된 비트스트림단에서 화질 평가를 수행하는 NR-B (No Reference Bitstream) 방법이 있다. 전송오류가 없을 경 우 일반적으로 화질 평가 방법에서 가장 정확한 방법은 원 본영상의 정보 전체를 사용하는 전체기준법이 가장 정확한 방법이나 자원이 제한된 비디오 전송에서는 적절한 방법이 아니다. 반면에 무기준법 동영상 화질평가 방법은 원본 동 영상의 정보나 추가적인 데이터가 필요하지 않기 때문에

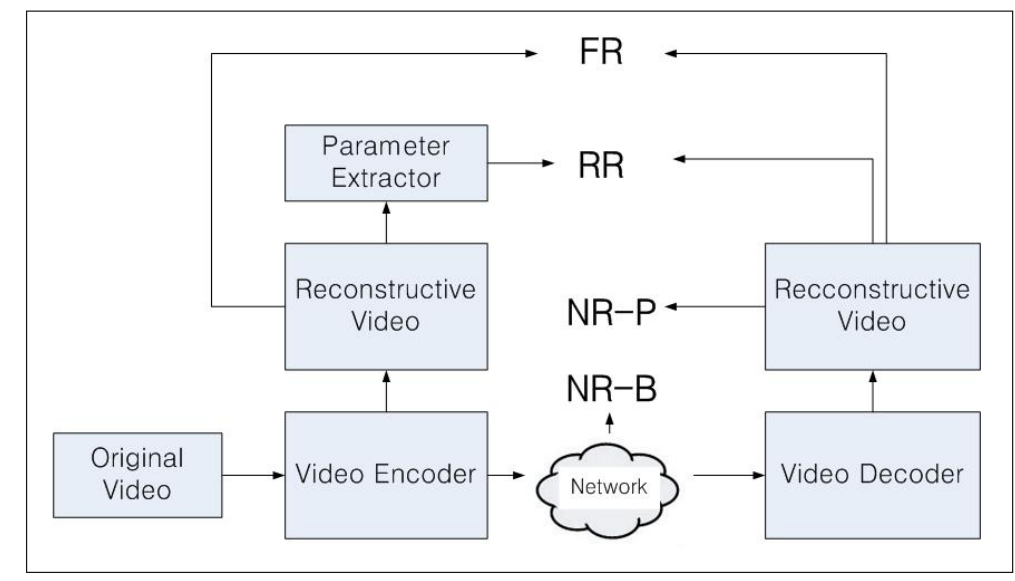

그림 1. 객관적 화질 평가의 종류

Fig 1. The type of objective quality assessments 
비디오 전송환경에 적합한 방법이다. 기존의 무기준 동영 상 화질 평가 방법에는 blockiness, blurring등을 측정하여 픽셀단에서 적용하는 방법 [4],[5] 과 양자화 파라미터, 에 러 전파 모델, 에러은닉기법 등을 고려하여 비트스트림단 에서 화질 평가를 수행하는 방법 [6],[7]이 있다. 하지만, 이 들 방법은 PSNR을 바탕으로 하여, 사람이 인지하는 화질 열화을 반영하지 않은 문제점이 있다. 본 논문에서 제안하 는 방법은 인지적인 관점에서의 NR-B방법을 사용하여, 실 시간 동영상 전송 환경에서 적용할 수 있는 실용적이고 간 단한 무기준법 화질 평가 방법을 제안한다.

\section{III. 주관적 화질 평가}

\section{1. 화질 평가 방법}

동영상의 화질과 화질 평가 파라미터의 상관도를 얻기 위해서 주관적 화질 평가 방법을 이용하여 실험영상의 $\operatorname{MOS}($ Mean Opinion Score)를 측정하였다. 주관적 화질 평 가에 사용한 방법은 ITU-T P.910 ACR 방법에 따라 실험 을 진행하였다. 본 논문에서 사용한 주관적 화질 평가 실 험 방법은 그림 2 와 같이 10 초 이내의 실험영상을 실험자 가 관찰한 후 화질에 따라 매우 나쁨, 나쁨, 보통, 좋음, 매우 좋음 5 단계로 나누어 이를 각각 1 에서 5 점까지의 수 치로 변환한다. 주관적 화질 평가에 참여한 실험자는 20 명 의 성균관대학교 정보통신공학부의 학부생이 참여하였으 며, 그림 3과 같은 프로그램을 제작하여 주관적 화질 테스

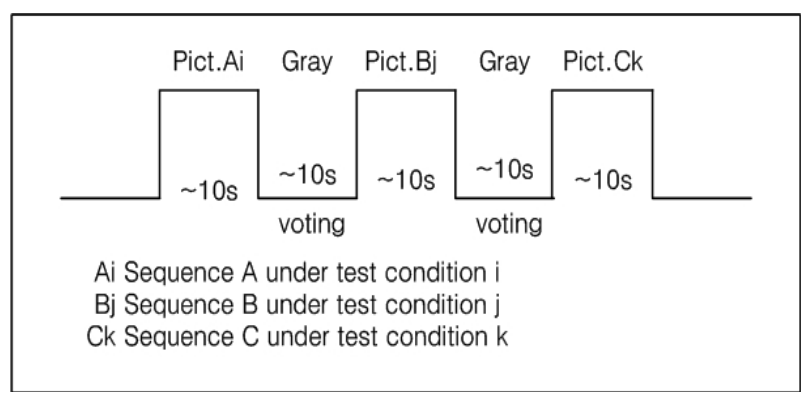

그림 2. 주관적 화질 평가 방법

Fig 2. Subjective MOS Test Method
트를 실시하였다.

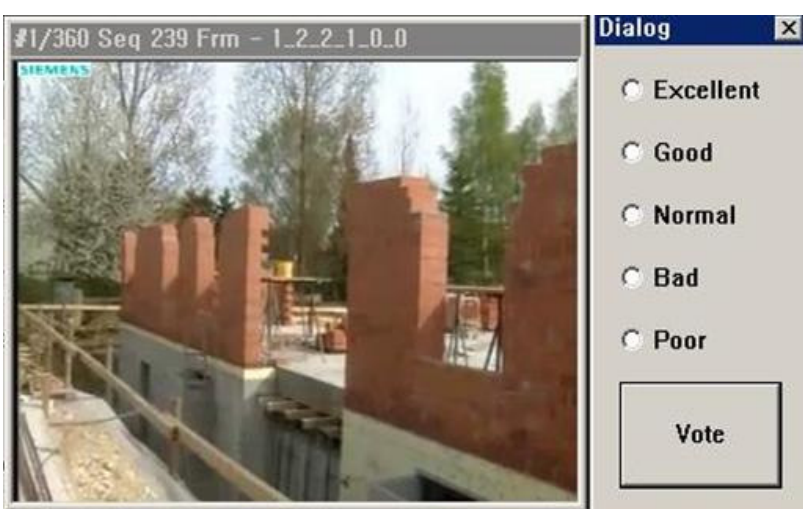

그림 3. 주관적 화질 평가 테스트 프로그램

Fig 3. Test Program

\section{2. 주관적 화질평가 환경}

화질평가에서 사용된 실험영상은 그림 4의 (a), (b) ,(c)와 같이 foreman, football, mobile 세 가지 영상을 사용하였다. 각 영상의 길이는 8초이며, H.264/AVC Baseline Profile $\left(\mathrm{JM} \mathrm{12.4}{ }^{[8]}\right)$ 을 사용하여 부호화하였다. 부호화 옵션은 표 1 에 나타낸 것과 같이 Baseline profile, IDRPP...P의 15의 길이를 갖는 $\mathrm{GOP}$ 구조를 사용하였으며 3종류의 양자화 파 라미터(28, 32, 36), 2종류의 해상도(QCIF, QVGA), 2종류 의 프레임 레이트( $15 \mathrm{fps}, 30 \mathrm{fps})$ 를 사용하였다. 에러 패턴은 SVC/AVC loss simulator [9]를 사용하여 총 0에서 14번 프 레임중에 1 번, 5 번, 10 번 프레임에 에러를 발생시켰으며, 각각의 위치에서 1 3개의 연속적인 에러를 발생시켜 9가지 의 에러패턴을 발생시켰다. 이는 영상의 초반부, 중반부, 후 반부에 각각 1 3개의 에러를 발생시켰음을 뜻한다. 에러

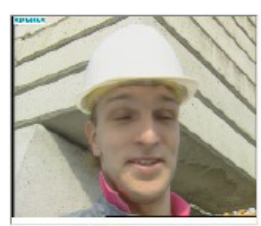

(a)

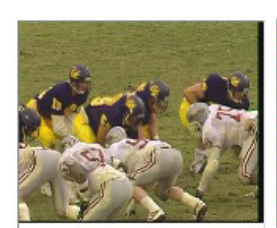

(b)

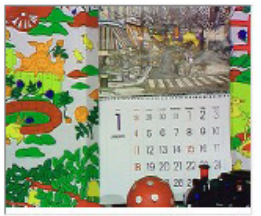

(c)
그림 4. 실험 영상

Fig 4. Test Sequence 
은닉기법은 Frame Copy 방법을 사용하였다.

표 1. 실험 환경

Table 1. Experiment Environment

\begin{tabular}{|c|c|}
\hline GOP Size & 15(IDRPPP....P) \\
\hline 양자화 파라미터 (QP) & 28 / 32 / 36 \\
\hline 프레임 해상도 & QCIF / QVGA \\
\hline 프레임 레이트 (FPS) & $15 \mathrm{fps} \mathrm{/} \mathrm{30fps}$ \\
\hline 프레임의 손실의 위치 & 1 / 5 / 10 번째 프레임 \\
\hline 연속에러 & 에러없음 / $1 / 2$ / 3 \\
\hline
\end{tabular}

\section{IV. 제안된 방법}

본 논문에서는 동영상 전송과정에서 발생하는 화질 열화 를 부호화 과정에서 발생하는 화질 열화와, 전송과정에서 발생하는 화질 열화 그리고 동영상의 움직임 정도에 따라 서 인지적인 화질 열화로 분류하여, 각각의 화질 열화를 예 측하여 동영상의 최종 화질을 예측한다.

\section{1. 에러 모형}

비디오 화질 평가의 국제 전문가 단체인 $\mathrm{VQEG}$ 의 Hybrid /Bitstream Group Test plan [10]으로부터 아래와 같은 수식 이 유도된다.

$$
D M O S=5+[\operatorname{MOS}(P V S)-\operatorname{MOS}(S R C)]
$$

식 (1)에서 $\mathrm{MOS}(\mathrm{PVS})$ 는 원본 동영상의 화질 평가 값이 며, $\operatorname{MOS}(\mathrm{SRC})$ 는 수신된 영상의 화질 평가 값이다. 따라서 식 (1)은 아래와 같이 나타 낼 수 있다.

$$
D M O S_{\text {est }}=5-D
$$

예측된 $\mathrm{DMOS}$ 는 동영상의 최대화질인 5 에서 화질 열화 정도를 뺀 값이다. $\mathrm{D}$ 는 화질 열화정도를 나타낸다. 본 논문 에서는 동영상 전송과정에서의 발생할 수 있는 화질 열화
를 양자화 과정에서의 화질 열화, 전송 과정에서의 화질 열 화 그리고 동영상의 움직임에 따른 화질 열화가 발생할 수 있다고 가정한다.

따라서 식 (2)는 아래와 같이 나타낸다.

$$
D M O S_{\text {est }}=5-\left(D_{Q}+D_{T}+D_{M}\right)
$$

$D_{Q}$ 는 양자화로 인하여 발생된 화질 열화이고, $D_{T}$ 는 전 송과정에서 발생한 화질 열화이며, $D_{M}$ 은 동영상의 움직임 정도에 따른 사람이 느끼는 화질 열화이다.

\section{2. 양자화 과정에서의 화질 열화}

동영상 부호화기는 양자화 과정에서 원본 영상의 정보의 손실이 발생하며, 이로 인해 화질 열화가 발생한다. 양자화 는 양자화 파라미터에 의해 그 강도를 조절 하게 되는데, 양자화 파라미터의 값이 크면 화질 열화가 많이 발생하며, 값이 작은 양자화 파라미터를 사용하게 되면 양자화 과정 에서의 화질 열화가 적게 발생한다. 따라서 양자화에 의한 화질 열화는 아래의 식과 같다.

$$
D_{Q}=w 1^{*} Q P
$$

$\mathrm{w} 1$ 는 양자화 과정에서 발생하는 화질 열화의 가중치 값 이며, $\mathrm{QP}$ 는 양자화 파라미터이다.

\section{3. 전송과정에서의 화질 열화}

동영상 전송과정에서 패킷 손실로 인한 화질 열화가 발 생할 수 있다. 일반적인 동영상 코덱에서는 화면간 압축기 법을 사용하기 때문에, 패킷 손실로 인한 화질 열화는 $\mathrm{GOP}$ (Group of Pictures)내에서 전파되는 현상이 있다. 이 를 에러 전파현상이라고 하며, 이를 측정하기 위한 에러 전파 모델을 가정할 필요가 있다. 기존의 에러 전파 모델 을 제안한 논문 ${ }^{[1]}$ 에서 사용된 방법은 너무 복잡하여, 실 시간 화질 평가 환경에서 적용하기 어렵다. 따라서 좀 더 


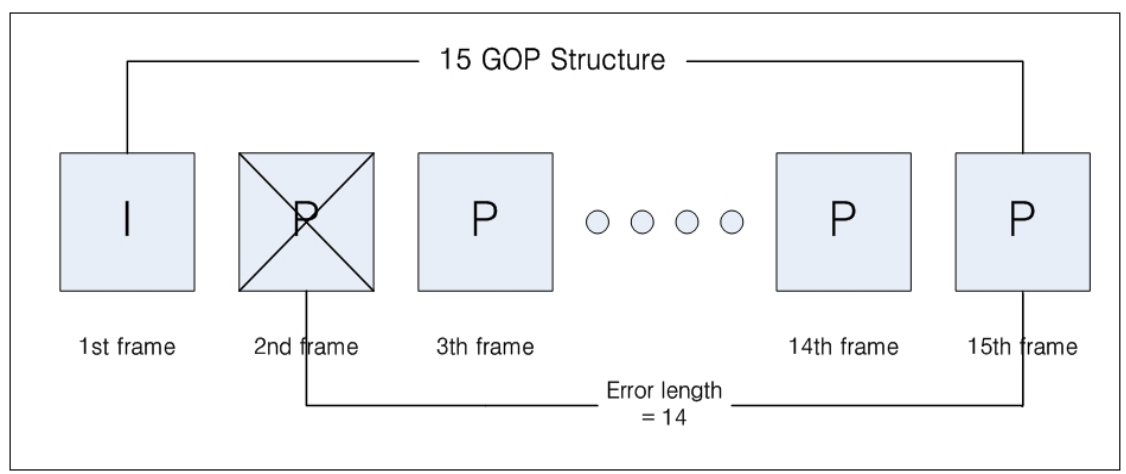

그림 5. 단일 에러 모델

Fig 5. Single Error Model

간단한 에러 전파 모델을 가정할 필요가 있다. 본 논문에 서 사용한 에러 전파 모델은 에러 전파 길이를 측정하는 방법을 사용하였다 ${ }^{[6}$. 예를 들어, 그림 5와같이 2번째 프레 임의 손실시 새로운 인트라 프레임이 나타나기 전까지는 에러가 전파 된다고 가정하며, 이 경우의 에러 전파 길이 는 14 가 된다.

따라서 $\mathrm{i}$ 번째 프레임의 에러전파 길이 $E L_{i}$ 는 식 (5)와 같이 나타낼 수 있다.

$\left\{E L_{i}=N_{G O P}-f_{i}\right.$, 손실이 발생했을경우

, 손실이 발생하지 않았을 경우

식 (5)에서 $N_{G O P}$ 는 $\mathrm{GOP}$ 에 포함되어 있는 프레임의 개수
이며 $f_{i}$ 은 전송 손실로 인하여 손실된 프레임의 위치이다. 이와 같은 방법으로 다중 에러에 따른 에러 전파 모델을 간단히 만들 수 있는데, 그림 6과 같다. 다중 에러 전파 모 델은 손실이 발생된 프레임의 에러 전파 길이의 합으로, 한 $\mathrm{GOP}$ 내의 에러 전파 길이를 측정한다.

따라서 프레임의 손실에 따른 화질 열화 $D_{T}$ 는 식 (6)과 같다.

$$
D_{T}=w 2 * \sum_{i=0}^{N_{G O P}-1} E L_{i}
$$

식 (6)에서 w2는 에러전파 길이에 의한 가중치이며,

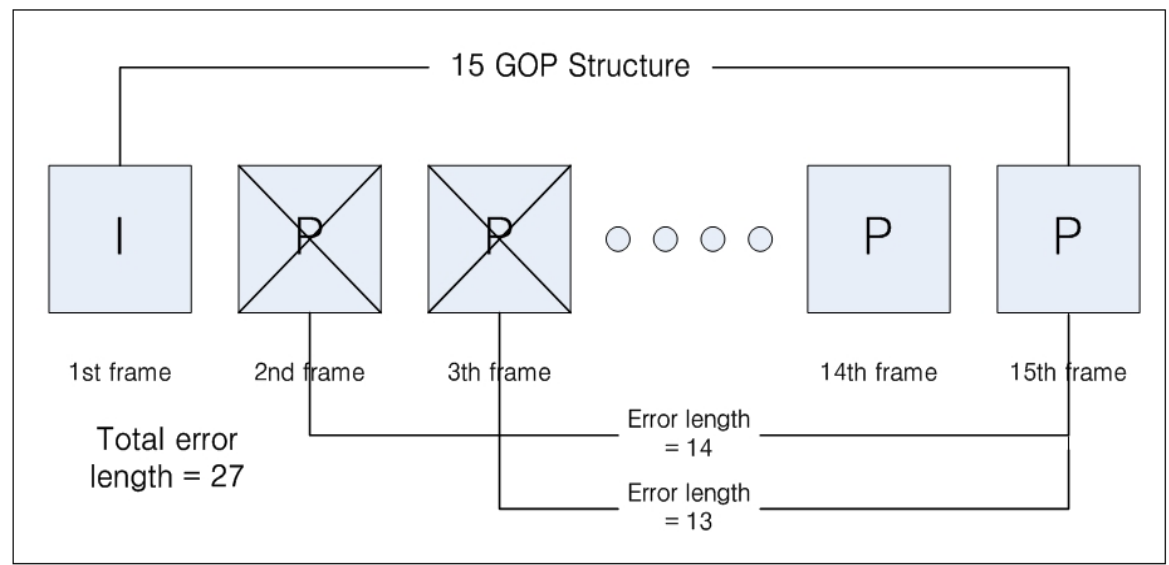

그림 6. 다중에러의 에러 모델

Fig 6. Multiple Error Model 
$N_{G O P}$ 은 $\mathrm{GOP}$ 의 길이, $E L_{i}$ 은 각 단일에러로 인하여 발생된 에러전파의 길이이다.

\section{4. 움직임 정도에 따른 화질 열화}

기존의 논문 [12] 에서 연구한 결과 움직임 정도가 큰 동 영상의 화질이 움직임이 작은 동영상의 화질보다 인지적인 화질 평가에서는 낮게 나타난다. 본 논문에서는 움직임 벡 터를 이용하여 동영상의 움직임 정도를 추정하여 화질평가 의 파라미터로 사용한다.

$$
M A_{i}=\frac{\sum|m v|}{w^{*} h}
$$

식 (7)에서 $\mathrm{mv}$ 는 매크로 블록의 움직임 벡터, $\mathrm{w}$ 는 프레 임의 넓이, $\mathrm{h}$ 는 프레임의 높이이다. 따라서 $\mathrm{i}$ 번째 프레임의 움직임 정도 $M A_{i}$ 는 각 매크로 블록의 $\mathrm{mv}$ 의 합을 프레임 의 해상도로 나누어 구해진다.

매크로 블록의 움직임 벡터의 합을 프레임의 해상도로 나누는 이유는 그림 7과 그림 8과 같이 해상도가 높은 영상 에서는 움직임 벡터의 값이 크게 나타나기 때문에 1픽셀당 움직임 정도를 측정하는 것이 요구된다.

움직임 정도에 의한 화질 열화는 아래의 수식과 같다.

$$
D_{M}=w 3 * \frac{\Sigma M A_{i}}{N}
$$

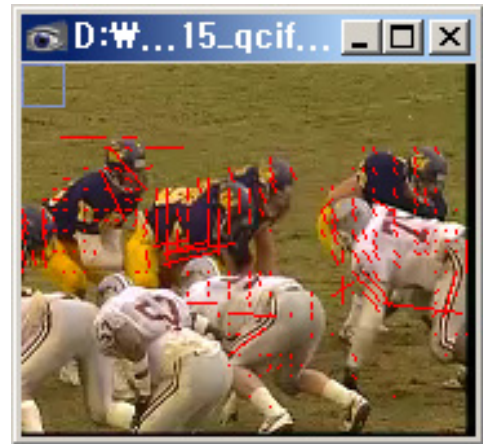

그림 7. QCIF 영상의 움직임벡터

Fig 7. Motion Vector of QCIF Video

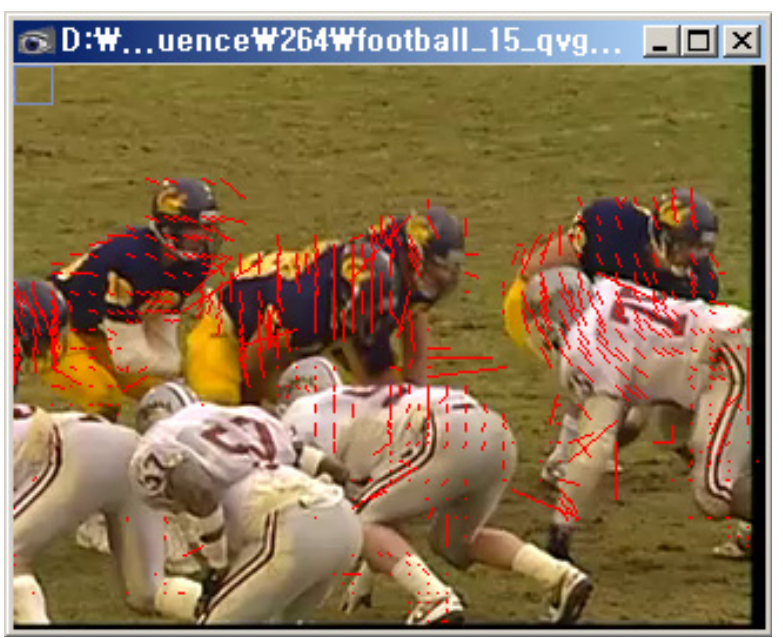

그림 8. QVGA 영상의 움직임 벡터

Fig 8. Motion Vector of QVGA Video

식 (8)에서 w3은 움직임 정도에 따른 화질 가중치이고 $\mathrm{N}$ 은 한 GOP내의 프레임의 개수 이며, 움직임 정도에 따른 화질 열화 $D_{M}$ 은 각 프레임의 움직임 정도의 평균으로 구 할 수 있다.

\section{DMOS 예측 모델}

1 4절에서의 식 (4), (6), (8)을 이용하여, 총 화질 열화 정도를 구하였다.

$$
D=w 1 * Q P+w 2 * \sum_{i=0}^{N-1} E L_{i}+w 3 * \frac{\Sigma M A}{N}
$$

최종 예측 $\mathrm{DMOS}$ 값을 구하기 위해서는 각 파라미터의 적절한 가중치 $\mathrm{w} 1, \mathrm{w} 2, \mathrm{w} 3$ 의 값을 구해야 된다. 파라미터 의 가중치 값을 구하기 위해서 Minitab $15.0^{[13]}$ 을 이용해서 3 장에서 주관적 화질 평가에 사용된 360개의 영상에 대한 회귀 분석을 실시하였다. 그 결과 주관적 화질 평가와 비교 하였을 때 가장 높은 상관도를 갖는 파라미터의 가중치 값 은 각각 $0.00463,0.00986,0.0505$ 이었다.

회귀 분석을 통해 구한 파라미터의 가중치 값은 동영상 의 움직임벡터를 고려하여 구한 값이기 때문에, 동영상 시 
퀀스의 종류에 관계없이 적용할 수 있으나, 다른 비디오 코 덱을 사용하거나 다른 해상도의 비디오를 사용하였을 경우 에는 각 가중치 값들은 변경될 수 있다.

\section{V. 실험}

\section{1. 실험방법}

제안된 알고리즘의 성능평가를 위해서, NTIA에서 제안 한 Video Quality Metric [14][15] 방법과 비교하였다. 비교 한 영상은 3장에서 사용된 360 개의 영상을 사용하였다. NTIA방법은 원본영상과 비교하여 얼마나 화질 열화가 발 생했는가를 평가하는 방법으로 원본과 비교하여 화질 열화 가 전혀 없으면 ' 0 ' 화질 열화가 최대로 발생했을 경우 ' 1 ' 로 평가한다. NTIA의 VQM방법과 비교을 실시한 이유는 현재 비교할만한 적절한 NR방법을 찾기가 어려우며, 공개 된 프로그램을 사용할 수 있기 때문에 NTIA의 VQM방법 과 비교를 하였다. 다른 논문에서 제안한 NTIA VQM방법 에서 1 이상의 값이 발생할 수 있는데, 이는 화질평가 범위 를 벗어나므로 평가에서 제외하였다. 성능 평가 방법은 3장 에서 실시한 주관적 화질평가 결과와 Pearson 상관도를 측 정하였다. Pearson 상관도는 $\mathrm{VQEG}$ 의 Hybrid /Bitstream Group Test Plan [10]에서 권고하는 화질평가 상관측정 방
법이다. Pearson 상관도는 아래와 같다.

$$
R=\frac{\sum_{i=1}^{N}\left(X_{i}-\bar{X}\right) *\left(Y_{i}-\bar{Y}\right)}{\sqrt{\Sigma\left(X_{i}-\overline{X)^{2}}\right.} * \sqrt{\Sigma\left(Y_{i}-\overline{Y)^{2}}\right.}}
$$

$X_{i}$ 는 주관적 화질 평가의 $\mathrm{DMOS}$ 값이며, $Y_{i}$ 는 예측된 화질 평가 값이다. $\mathrm{N}$ 은 테스트한 전체 비디오 샘플이다. Pearson 상관도 값이 1 이면, 두 변수는 선형관계에 있다는 것을 의미하며, 0 이면 두 변수는 서로 독립임을 의미한다.

\section{2. 실험결과 및 분석}

본 논문에서 제안된 방법과 NTIA VQM방법의 주관적 화 질 평가 방법과의 Pearson 상관도는 표 2와 같다. 평균 Pearson 상관도 값은 NTIA VQM방법은 0.794 , 제안된 방법은 0.856 으로 제안된 방법의 성능이 약 $8 \%$ 정도 개선되었다.

Table 2. Pearson Correlation 표 2. Pearson 상관도

\begin{tabular}{|c|c|c|}
\hline & NTIA VQM & 제안된 방법 \\
\hline QCIF & $\underline{0.738}$ & $\underline{0.874}$ \\
\hline QVGA & $\underline{0.816}$ & $\underline{0.821}$ \\
\hline 평균 & $\underline{0.794}$ & $\underline{0.856}$ \\
\hline
\end{tabular}
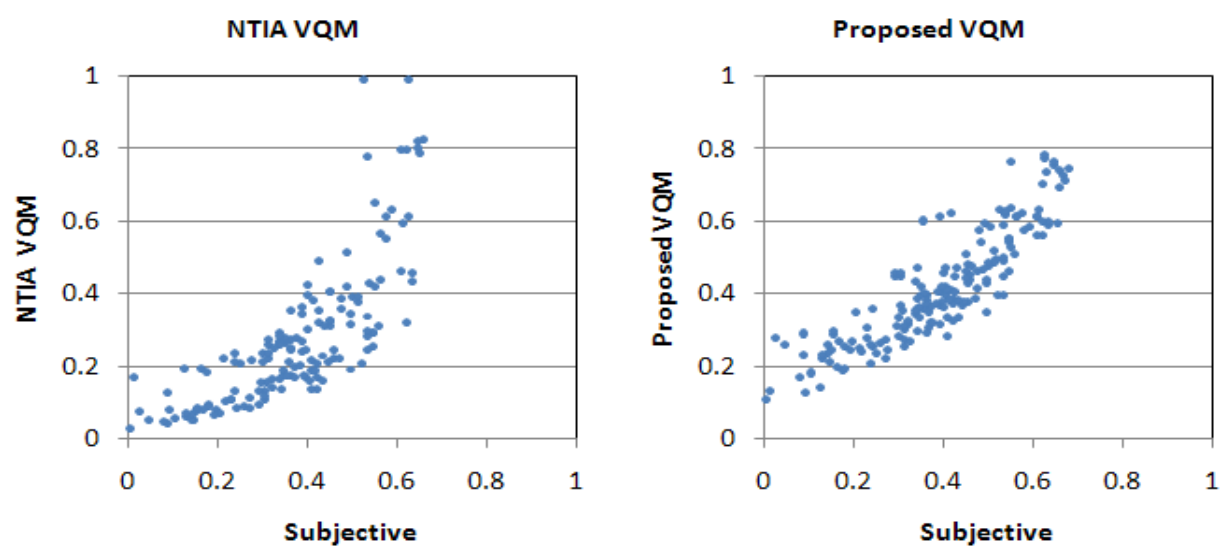

그림 9. NTIA 방법과 제안된 방법의 상관도 (QCIF)

Fig 9. Correlation of NTIA method and proposed method (QCIF) 

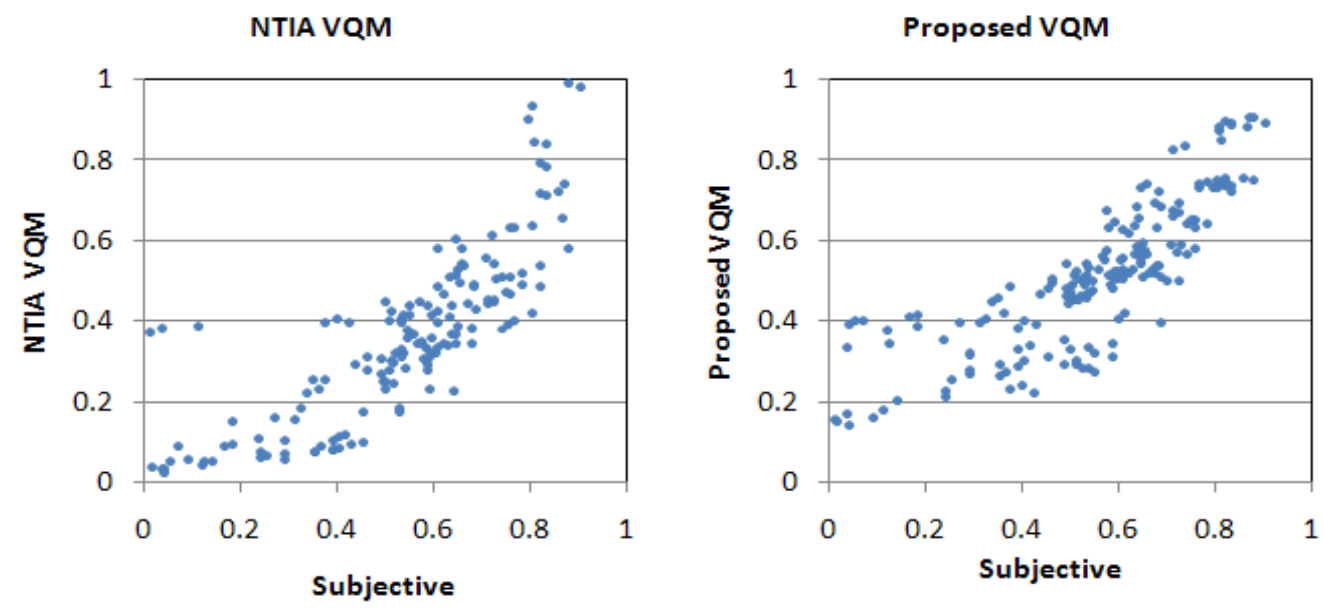

그림 10. NTIA 방법과 제안된 방법의 상관도 (QVGA)

Fig 10. Correlation of NTIA method and proposed method (QVGA)
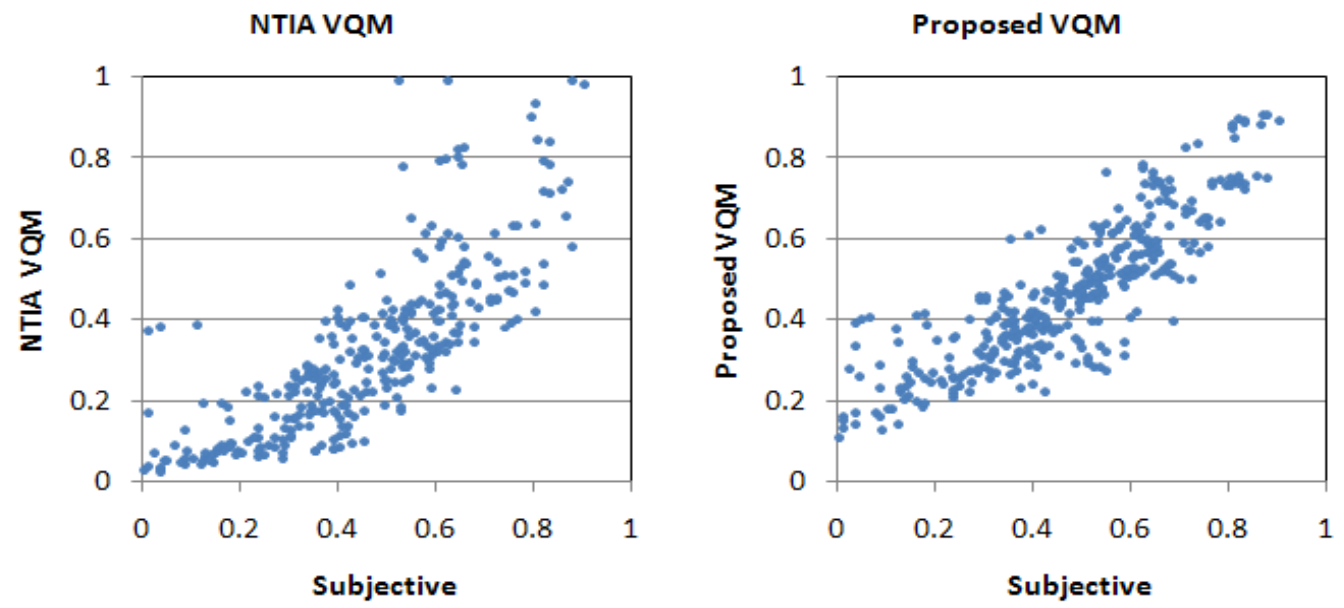

그림 11. NTIA 방법과 제안된 방법의 상관도 (전체)

Fig 11. Correlation of NTIA method and proposed method (Total)

그림 9와 10 은 각각 $\mathrm{QCIF}$ 영상과 $\mathrm{QVGA}$ 영상의 성능 비 교 방법이며, 그림 11은 전체 시퀀스의 성능 그래프이다. 그 래프를 통해서 제안된 방법의 상관도가 NTIA방법 보다 높 게 나타났다. 이는 일반적인 환경에서 제안된 방법이 NTIA 의 방법보다 우수하다는 것을 뜻하는 것은 아니다. 본 논문 에서 제안된 방법의 상관도가 NTIA의 방법보다 상관도가 높은 이유는 NTIA의 방법은 전송오류에 관한 영향을 고려 하지 않은 방법고, SDTV에 최적화된 방법이기 때문이다.

\section{VI. 결론 및 향후 계획}

본 논문에서는 비트스트림 파라미터를 이용하여 패킷 비 디오 네트워크에서 실시간 스트리밍 서비스에 적용 할 수 있는 무기준법 동영상 화질 평가 방법을 제안하였다. 코덱 에서 발생하는 화질 열화를 고려한 양자화 파라미터, 전송 과정에서 발생될 수 있는 전송에러 파라미터, 인지적인 관 점에서 화질 열화를 발생 시키는 움직임 정도를 이용하여 
화질평가의 정확성을 높였다. 실험 결과에 따르면 $\mathrm{CIF}$ 영상 의 상관도가 QVGA의 상관도보다 더 높은 것을 알 수 있다. 본 논문에서는 두 가지 크기의 영상을 실험 영상을 사용하 였기 때문에 정확한 분석은 어려우나 향후 테스트 영상의 종류를 다양화 하여 영상의 크기에 따른 화질 평가에 관한 연구가 진행될 예정이다.

무기준법 동영상 화질 평가 기술은 전체기준법이나 부분 기준법 화질 평가에 비하여 원본 영상이나 추가적인 데이 터가 필요하지 않기 때문에 모바일 IPTV, Video Telephone 등에서 사용자 관점에서의 서비스 품질을 보장하기 위해 적절한 방법이다. 본 논문에서는 제한적인 환경에서 무기 준법에 의한 동영상 화질 평가 방법을 사용하여, 만족할만 한 결과을 얻었지만, 향후 더 많은 종류의 동영상을 이용하 여 일반적으로 적용할 수 있는 무기준법 화질 평가 알고리 즘을 개발하는 연구가 필요하겠다.

\section{참 고 문 헌}

[1] B. Girod, "What's wrong with mean-sqared error", Digital Images and human Vision, MIT Press, pp. 207-220, 1993

[2] VQEG Web Site, "http://www.its.bldrdoc.gov/vqeg/"

[3] ITU-T P.910 "Subjective Video Quality Assessment Methods For
Multimedia Applications"

[4] Zhou Wang, "Blind measurement of blocking artifacts in images" Proc. IEEE Int. Conf. Image Proc, 2000

[5] Pina Marziliano, "A No-Reference perceptyal blur metric" Proc. IEEE Int. Conf. Image Proc, 2002

[6] Tao Liu "Subjective Quality Evaluation of Decoded Video in the Presence of Packet Losses", ICASSP, 2007

[7] Yamada, Toru, Miyamoto, Yoshihiro, Serizawa, Masahiro "NoReference Video Quality Estimation Based on Error-Concealment Effectiveness" Packet Video 2007, 2007

[8] H.264/AVC JM Reference Software home page, "http://iphome.hhi. de/suehring/tml"

[9] Yi Guo, Houqiang Li “"SVC/AVC loss simulator”", JVT-Q.069

[10] VQEG "Hybrid Perceptual/Bitstream Group Test Plan Draft Version $1.3 ", 2009$

[11] J.-G.Kim, J. Kim, J. Shin, and C.-C. J. Kuo, "Coordinated packet-level protection with a corruption model for robust video transmission," in Proc. of SPIE Visual Communications and Image Processing, pp.410-421, Dec. 2000

[12] Stephen D. Voran, Stephen Wolf, "An objective video quality assessment system based on human perception", SPIE Human Vision, Visual Processing and Digital Display, 1993

[13] Minitab homepage, "http://www.minitab.co.kr/minitab/index.asp"

[14] ITU-T J.144 "Objective perceptual video quality measurement techniques for digital cable television in the presence of a full reference"

[15] ITS Video Quality Research home page, "http://www.its.bldrdoc. gov/ n3/video/"

\section{저 자 소 개}

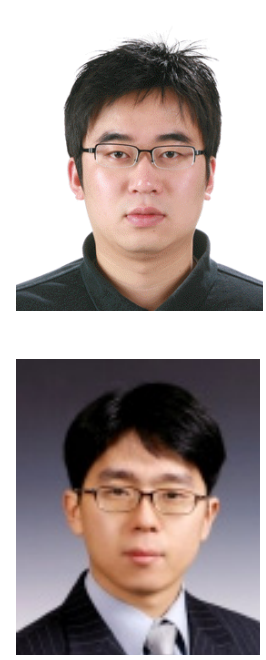

\section{성 덕 구}

- 2008년 : 경희대학교 전자공학과 학사

- 2008년 현재 : 성균관대학교 정보통신공학부 석사과정

- 주관심분야 : SVC, 멀티캐스트, MIMO

\section{김 요 한}

- 2001년 : 아주대학교 전자공학부 학사

- 2003년 : 아주대학교 전자공학과 석사

- 2003년 2004년 : Gtran Wireless H/W1팀 연구원

- 2005년 2006년 : Pantech 중앙연구소 UMTS H/W3팀 연구원

- 2007년 현재 : 성균관대학교 휴대폰학과 박사수료

- 주관심분야 : WCDMA, SVC, 멀티캐스트, MIMO 
저 자 소 개

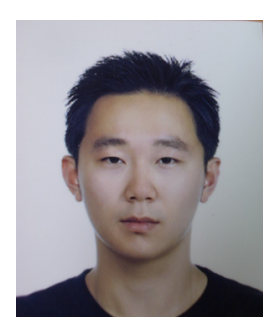

\section{한 정 현}

- 2009년 : 성균관대학교 정보통신계열 전자전기전공 학사

- 2009년 현재 : 성균관대학교 정보통신공학부 석사과정

- 주관심 분야 : SVC, DVC, 멀티캐스트, MIMO

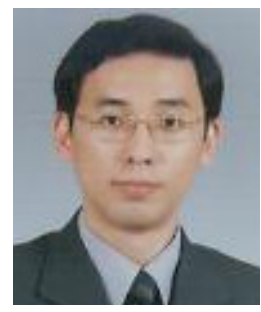

\section{신 지 태}

- 1986년 : 서울대학교 전기공학과 학사

- 1988년 : KAIST 원자력공학과 석사

- 2001년 : Univ. of Southern California, 전기전자공학과 석사박사

- 1988년 3월 1991년 10월 : 한국전력공사 고리원자력발전소 계측제어부 전문원

- 1991년 11월 1996년 8월 : 한국원자력연구소 계측제어설계부 선임연구원

- 2001년 8월 2002년 2월 : 경희대학교 정보통신전문대학원 교수

- 2002년 3월 현재 : 성균관대학교 정보통신공학부 부교수

- 주관심분야 : 멀티미디어 통신/네트워크, 이동휴대 방송기술, 유무선 통신네트워크 시스템, 영상처리 